\title{
Intent to remember briefly presented human faces and other pictorial stimuli enhances recognition memory
}

\author{
RICHARD A. BLOCK \\ Montana State University, Bozeman, Montana
}

\begin{abstract}
Since the early days of psychology, researchers have investigated whether or not intending to remember information affects subsequent memory performance. The literature contains methodological issues and empirical contradictions, with ambiguous effects. In five experiments, a total of 576 participants viewed a rapid series of pictorial stimuli under either incidental- or intentional-memory conditions. Although the methodology was stringent, intent to remember consistently enhanced recognition memory. Recognition was enhanced even when participants viewed a picture of a human face, of an ape face, or of a bird for as little as $0.5-1.0$ sec, with no interstimulus interval between it and the next picture. Rehearsal, depth of processing, and attentional allocation are discussed to explain how people might intentionally encode pictorial information to enhance their subsequent recognition memory performance.
\end{abstract}

Does intending to remember information enhance the subsequent remembering of it? If intending to remember information does improve memory, how quickly can attentional or working memory resources be allocated to enhance long-term remembering? Interestingly, the Latin origin of the words intend and attend is intendere, which is translated as "to direct one's attention." In the present experiments, the basic manipulation is that some people encode information without awareness that a memory test will follow (henceforth, incidental memory or incidental condition), whereas other people encode the same information with awareness that a memory test will follow (henceforth, intentional memory or intentional condition). Following the presentation of a series of pictorial stimuli, recognition memory was tested.

\section{Early Studies}

Scientific studies of the effects of incidental versus intentional memory date to the early days of experimental psychology (Meumann, 1913; Shellow, 1923). (The near-synonymous terms incidental learning and intentional learning usually refer to conditions in studies of the rate at which people acquire a perceptual motor skill or a verbal learning task.) During the 1950 s and 1960s, research sometimes revealed positive effects of intent to remember on memory performance (e.g., Neimark \& Saltzman, 1953; Postman \& Phillips, 1954; Saltzman \& Atkinson, 1954; Saltzman \& Carterette, 1959). However, as Saltzman (1953) noted, many studies contained a serious confounding: "In the previous studies, ... the incidental learners were not given instructions to learn, but were required to perform [an] orienting task. The intentional learners ... were given instructions to learn, but were not required to perform [an] orienting task" (p. 596).

Eagle and Leiter (1964) found an interaction between memory condition and type of memory test. Participants heard a series of 36 words at about a 4 -sec rate; this was followed by a recall test and, subsequently, by a recognition test. In one condition, the participants were told simply to try to remember the words for a recall test. In two other conditions, the participants performed an orienting task (indicating whether each presented word was a noun, a verb, or an adjective), with some participants in an incidental condition and some in an intentional condition. Participants who performed the orienting task showed no effect of intent to remember on either recall tests or recognition tests. However, there was an interesting interaction: In comparison with participants in the orienting-task conditions, participants in the intentionalmemory condition (who performed no orienting task) recalled more words $(p=.001, d=0.72)$ but recognized fewer words $(p<.001, d=0.85) .{ }^{1}$ This finding suggests that intent to remember may facilitate recall but impair recognition memory; however, this interaction could have resulted from the fact that the participants in the intentional condition expected a recall test. Estes and Da Polito (1967) reported similar findings, although their procedure confounded memory condition with whether or not (in incidental vs. intentional conditions) participants performed a secondary task during stimulus presentation. This is the same methodology that Saltzman (1953) had questioned earlier.

R. A. Block, block@montana.edu 


\section{Levels-of-Processing Framework}

Postman (1964) concluded that "there is little or no reason to maintain a conceptual distinction between intentional and incidental learning" (p. 193). His skeptical view was based partly on earlier research on orienting tasks (i.e., information-processing activities that accompanied the presentation of to-be-remembered stimuli). This view was reinforced in the 1970s with the introduction of the levels-of-processing framework (Craik \& Lockhart, 1972), in which memory performance depended on the so-called depth of an orienting task but not much, if at all, on whether or not participants were instructed to remember presented information. Hyde and Jenkins (1973) conducted the research that is the most frequently cited. They used four kinds of orienting tasks, each under an incidental or intentional condition. They found a large effect of orienting task on word recall. For example, under incidental conditions, participants who had judged whether each presented word was pleasant or unpleasant recalled more words than did those who had judged whether or not each presented word contained the letters $e, g$, or both $(p<.001, d=2.17)$. Hyde and Jenkins also included a control condition, in which there was no orienting task, but only instructions to intend to remember the presented words. The number of words recalled in this condition was not lower than that recalled in an incidental condition using the orienting task that produced the best recall: pleasant-unpleasant ratings ( $p=.11, d=0.29$ ). Most important, across all four orienting tasks, Hyde and Jenkins also found an effect of incidental versus intentional condition (especially when associated, rather than unrelated, information was used) - a significant but small effect $(p<.001, d=0.30)$.

Hyde and Jenkins's (1973) study - along with other levels-of-processing studies, in which intent to remember was not manipulated-led to a considerable increase in research on levels of processing and a considerable decrease in research on intent to remember. Some reviewers of that study were accurate. For example, Zechmeister and Nyberg (1982) said that retention following intentionalmemory instructions is as good as that following a semantic orienting task. Other reviewers were less accurate. For example, Willingham (2007) said that "the Hyde and Jenkins (1973) study shows that intention to learn has no effect at all" (p. 184).

Bower and Karlin (1974) conducted another relevant study. They presented human faces at a 5 -sec rate, and participants were asked to judge the sex, likableness, or honesty of each face. Subsequent recognition memory performance was higher on faces for which participants had judged the likableness or honesty than on those for which participants had judged the sex of the face. This is a typical levels-of-processing effect. However, recognition following incidental instructions and recognition following intentional instructions were "quite similar" (p. 754) for all three kinds of judgment (sex, likableness, and honesty). In short, recognition memory for human faces was not influenced by intent to remember.

Although Hyde and Jenkins (1973) found small but significant effects of intent to remember, Bower and Karlin
(1974) did not. Taken together, these and other studies had a chilling effect on research concerning intent to remember. As a result, during the past several decades, few researchers have investigated differences between incidental and intentional conditions.

\section{Intent to Remember and Automaticity}

Intent to remember is closely related to theories of automaticity: Incidental conditions presumably access component processes that occur automatically, whereas intentional conditions presumably access component processes that are controlled (although component processes that are automatic may also be involved). Several criteria are used for determining whether or not a process is automatic (Hasher \& Zacks, 1979, 1984; Posner \& Snyder, 1975; Schneider \& Shiffrin, 1977; Shiffrin \& Schneider, 1977). Automatic component processes must meet several criteria: They must occur without intent, and information that is encoded intentionally cannot differ from information that is encoded incidentally. Much of the extant evidence is either indecisive or comes from negative findings that reveal no effect of intent to remember. The present findings suggest that controlled encoding processes may be important when an information-processing task is assumed to involve mainly automatic encoding. In addition, these controlled processes may be more rapid than initially thought, occurring within several hundred milliseconds; this is important new evidence on the issue.

\section{How the Present Methodology Addresses Limitations of Previous Methodologies}

The present research was designed to test differences between incidental and intentional conditions using a more stringent methodology than those used in previous studies. Extant research on intentional versus incidental memory has often been limited in several main ways, which the present methodology sought to avoid:

1. In many experiments, the participants in the incidental condition were given an orienting task, presumably to ensure that they would attend to the stimuli, but also to prevent them from suspecting that memory for the stimuli would be tested. In the intentional condition, the participants did not perform the orienting task, but they were told simply to try to remember the presented information. This is a serious confounding (Saltzman, 1953).

2. Most researchers have used verbal stimuli, such as words. Differences between memory for words under incidental and intentional conditions can easily be attributed to differential rehearsal in the two conditions. Although large effects of intentional memory instructions are sometimes found when verbal stimuli are used (see, e.g., Neill, Beck, Bottalico, \& Molloy, 1990), little or no effect is usually found when pictorial stimuli (such as faces) are used (see, e.g., Bower \& Karlin, 1974). In order to minimize the possibility that any differences between incidental and intentional conditions could be attributed to differences in rehearsal strategies, I chose to use pictorial stimuli. Some early researchers (Hintzman \& Rogers, 1973; Shaffer \& Shiffrin, 1972) found that pictorial stimuli, unlike words, apparently cannot be rehearsed. Subsequently, other re- 
searchers reported that memory for pictorial stimuli may be enhanced if a blank interstimulus interval (ISI)usually called off time or rehearsal interval-follows the presentation of a pictorial stimulus, such as a human face (e.g., Read, 1979; Tversky \& Sherman, 1975; Watkins \& Graefe, 1981; Weaver, 1974). Importantly, however, no research has revealed that people can rehearse a pictorial stimulus when another pictorial stimulus follows it immediately. In order to minimize or rule out the possibility that any effect of intentional-memory instructions could simply be explained in terms of rehearsal, I presented pictorial stimuli with an ISI of $0 \mathrm{sec}$.

3. Previous researchers (e.g., Bower \& Karlin, 1974; Marmie \& Healy, 2004) have used relatively long stimulus durations, which may enable some participants to process information at deeper levels. I investigated shorter stimulus durations because some research (e.g., Neimark \& Saltzman, 1953) suggests that any memory enhancement under intentional conditions is attenuated at shorter durations.

4. Most previous studies have used a recall test. I used a recognition memory test, which is a stringent test of effects of intent to remember, because some research reviewed in the present article has revealed little or no facilitating effect (and even an impairing effect) of intent to remember when memory is assessed by using a recognition test instead of a recall test.

5. As described earlier, Bower and Karlin (1974) found no facilitating effect of intentional-memory instructions on recognition of human faces. Coin and Tiberghien (1997) reviewed that study and several other studies that used human faces as stimuli. They concluded that "the similarity of the results obtained with intentional and incidental conditions seems clearly demonstrated" (p. 549). In an attempt to further investigate this issue, I used human faces as stimuli in the present experiments. Some evidence suggests that early component processes involved in human face encoding are automatic, although other evidence suggests that effortful (controlled) processing may also modify the encoding and memory of some aspects of face information (for reviews, see Bruce, 1988; Ellis \& Young, 1989; Palermo \& Rhodes, 2007; Rakover $\&$ Cahlon, 2001; Young, 1998). Although "faces are not detected in the complete absence of attentional resources" (Palermo \& Rhodes, 2007, p. 85), human faces are a primary example of a type of stimulus that people encode in a relatively automatic way. Thus, effects of controlled processing strategies should be minimized.

Some participants in an incidental condition might deliberately try to remember presented stimuli, which could reduce the size of any effect of intentional-memory instructions. In order to minimize the likelihood of participants' attempts to remember, one or both of the following two methods must be used: (1) a cover story, in which all participants are told that the experiment focuses on something other than memory; and (2) a cover task, in which all participants are asked to perform a task that does not involve memory, as in most levels-of-processing experiments. In an excellent example of the use of both methods, Neill et al. (1990, Experiment 1) misinformed participants by saying that the experiment concerned reaction times and instructed the participants to press a key when each word disappeared from the screen. Only participants in the intentional condition were told that memory for the words would subsequently be tested. The present Experiments 1 and 5 used a cover story, whereas Experiments 2, 3, and 4 used a cover task.

\section{EXPERIMENT 1}

In Experiment 1, I investigated the extent to which human faces are encoded in a relatively automatic way, in a controlled way, or both. If people encode human faces without the involvement of any controlled processes, or if intent to remember has no effect on memory, instructing some participants to remember faces should not affect recognition performance. Half of the participants were informed that their memory for faces would subsequently be tested (intentional condition), whereas half were not informed about a subsequent memory test (incidental condition). In order to prevent participants in the incidental condition from suspecting that their memory for the faces would subsequently be tested (i.e., to minimize the likelihood that they would intend to remember the faces), Experiment 1 used a cover story.

\section{Method}

Participants. A total of 80 undergraduates (40 female) consented to participate in a study investigating how a person's mood is affected by crowds of people. ${ }^{2}$ They served in sessions of about 6-10 participants who were randomly assigned to the experimental conditions in an effort to include at least 1 participant of each sex in each condition.

Materials. A total of 40 faces ( 20 female) were created by using FACES (InterQuest, 1998) software, which enables one to generate unique monochrome faces. ${ }^{3}$ I used the "Random Faces" procedure, which samples randomly from all potential facial features. I then selected and altered the resulting faces to make them seem realistic.

Design and Procedure. A between-participants design (incidental vs. intentional) was used. In order to prevent participants in the incidental condition from effortfully trying to remember the faces, at the start of the experiment, I had all of the participants read written instructions that conveyed a cover story: It said that we were studying how a person's mood is affected by crowds of people and that we would show pictures of faces and later ask the participants to report their mood. The memory condition was manipulated by the presentation of written instructions that informed the participants in the intentional condition that they would subsequently be asked to recognize the faces that they saw. The participants in the incidental condition did not receive this information.

The participants then viewed 20 faces (10 female) presented at a 4.7-sec rate. The order of the faces was randomized; four different versions were used. The face stimuli were counterbalanced across whether each face was presented (old) or not presented (new). After the faces were presented, the participants were presented 40 test faces - 20 old (10 female) and 20 new (10 female), in a random order-and they were asked to make old-new recognition judgments. Each test face was shown for $8.0 \mathrm{sec}$.

\section{Results}

Recognition performance was analyzed using Snodgrass and Corwin's (1988) recommended methods. The hit rate was higher in the intentional $(M=.77, S E=.02)$ than in the incidental $(M=.68, S E=.02)$ condition $[t(78)=$ 
2.91, $p=.005, d=0.65]$. The false alarm rate did not differ between the intentional $(M=.12, S E=.01)$ and incidental $(M=.11, S E=.01)$ conditions $[t(78)=0.47]$. Recognition bias $\left(B_{\mathrm{r}}\right)$ did not differ between the intentional $(M=.28, S E=.03)$ and incidental $(M=.32, S E=$ $.03)$ conditions $[t(78)=0.84]$. The main theory-based evidence concerns recognition discrimination $\left(P_{\mathrm{r}}\right)$ in the two memory conditions. $P_{\mathrm{r}}$ was higher in the intentional $(M=.66, S E=.02)$ than in the incidental $(M=.57$, $S E=.03)$ condition $[t(78)=2.68, p=.009, d=0.60]$, although $P_{\mathrm{r}}$ was above chance in the incidental condition $[t(39)=20.8, p<.001] .^{4}$

\section{Discussion}

The findings of Experiment 1 reveal that participants who received intentional memory instructions to remember faces recognized them better than did participants in an incidental condition. However, recognition memory was above chance even in the incidental condition. These findings suggest that, although some component face-encoding processes may occur automatically, controlled face-encoding processes may add information to memory that enhances performance on subsequent recognition tests.

\section{EXPERIMENT 2}

Experiment 2 was designed to replicate and extend the findings of Experiment 1. I used a cover task instead of a cover story to minimize the likelihood that participants in the incidental condition would try to remember presented information. Two stimulus durations were used in order to investigate the question of how rapidly attentional resources can be allocated to enhance subsequent remembering under intentional conditions.
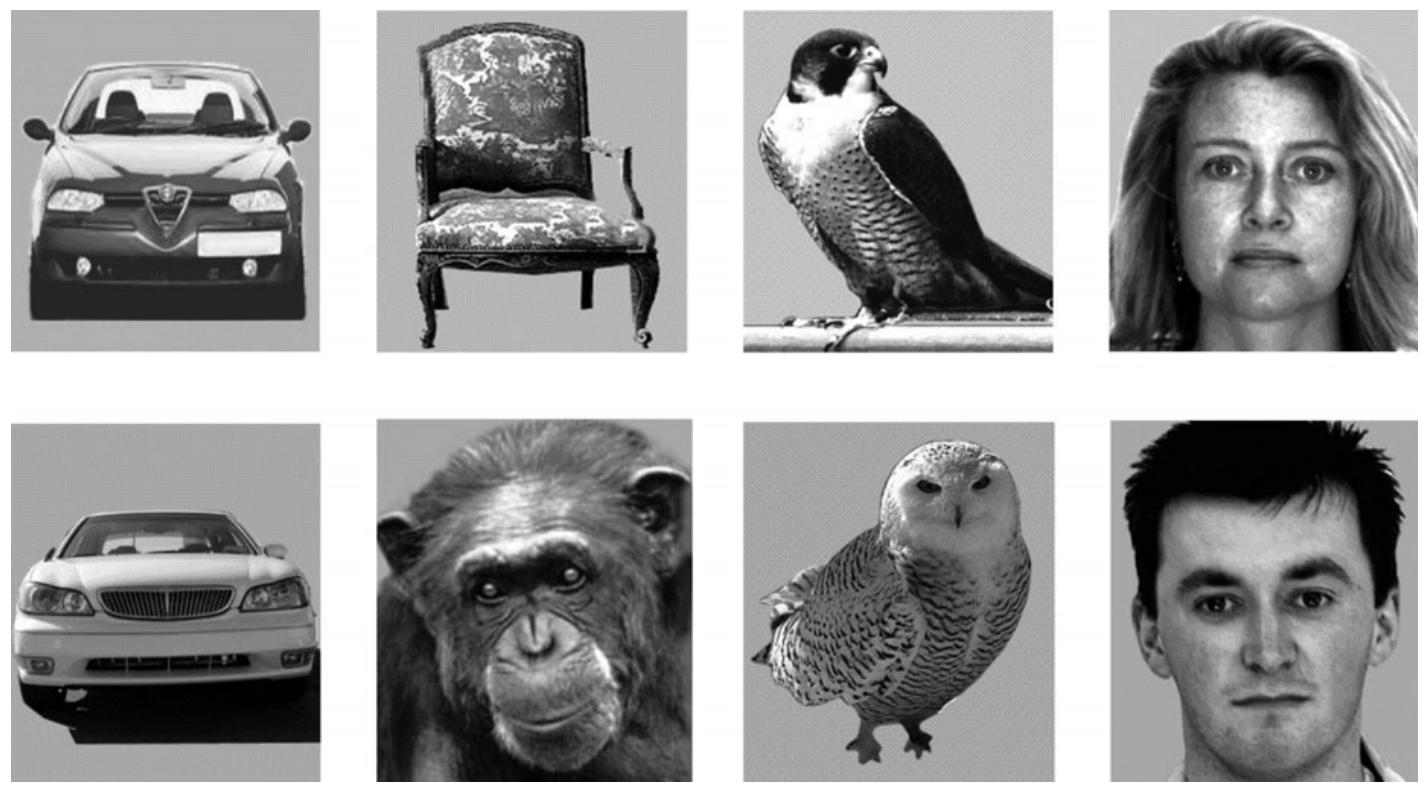

Participants. A total of 80 undergraduates ( 40 female) consented to participate in a study investigating how people process visual information.

Materials. From a large set of monochrome pictures that Carmel and Bentin (2002) used in their research on face encoding, I selected 18 pictures of cars, 18 of chairs, 18 of birds, and 40 of human faces (20 female; see Figure 1). The human faces - frontal photographs of women and men displaying relatively neutral facial expressionswere selected from the larger set to resemble typical North American faces.

Design and Procedure. A $2 \times 2$ mixed model design was used, with memory condition (incidental vs. intentional) manipulated between participants and stimulus duration ( 1.0 vs. $3.0 \mathrm{sec})$ manipulated within participants. In order to prevent participants in the incidental condition from effortfully trying to remember the faces, at the start of the experiment, I gave all of the participants a cover task: They read written instructions saying that they would see pictures of cars, chairs, human faces, and birds, and that their task was to count the total number of cars they saw. (Pilot studies revealed that this is a plausible cover story, that the task is easy, and that the task is performed with nearly $100 \%$ accuracy.) The memory condition was manipulated by the presentation of written instructions that informed the participants in the intentional condition that they would subsequently be asked to recognize the faces that they saw. The participants in the incidental condition did not receive this information.

The participants then viewed 74 stimuli-18 cars, 18 chairs, 18 birds, and 20 faces ( 10 female) - with half of the stimuli of each type presented for each of two stimulus durations $(1.0$ or $3.0 \mathrm{sec})$. The ISI was $0 \mathrm{sec}$. The order and stimulus duration of the various stimuli were randomized; four different versions were used. The individual face stimuli were counterbalanced across the two stimulus durations and whether or not each face was presented. After the pictures were shown, the participants were asked to report the total number of cars that they saw. They were then presented 40 faces -20 old (10 female) and 20 new (10 female), in a random order - and they were asked to make old-new recognition judgments. Each test face was shown for $8.0 \mathrm{sec}$.

Figure 1. An example of each type of stimulus used in Experiments 2 and 3 (top row) and in Experiments 4 and 5 (bottom row). 


\section{Results}

Several $2 \times 2$ (memory condition $\times$ stimulus duration) mixed model ANOVAs were conducted to compare performance in the various conditions. Planned comparisons ( $t$ tests) were conducted to clarify differences between theoretically important conditions.

Cover-task performance. The overall number of cars reported $(M=18.04, S E=0.17)$ did not differ from the actual number of 18 cars presented $[t(79)=0.22, p=.83]$. Participants in the intentional $(M=18.00, S E=0.26)$ and incidental $(M=18.08, S E=0.22)$ conditions showed comparable performance $[t(78)=0.22, p=.83]$.

Hit rate, false alarm rate, and recognition bias. The hit rate was higher in the intentional $(M=.64, S E=$ $.02)$ than in the incidental $(M=.51, S E=.02)$ condition $[F(1,78)=16.4, p<.001, d=0.64]$. The false alarm rate was lower in the intentional $(M=.17, S E=.02)$ than in the incidental $(M=.25, S E=.02)$ condition $[F(1,78)=$ $8.88, p=.004, d=0.67]$. $B_{\mathrm{r}}$ did not differ between the incidental $(M=.35, S E=.02)$ and intentional $(M=.31$, $S E=.02)$ conditions $[F(1,78)=1.12, p=.28]$.

Recognition discrimination. The main evidence concerns $P_{\mathrm{r}}$ in the two memory conditions at each of the two stimulus durations (see Figure 2). $P_{\mathrm{r}}$ was higher in the intentional condition than in the incidental condition $[F(1,78)=29.3, p<.001, d=0.85]$. Neither the main effect of stimulus duration nor the interaction between memory condition and stimulus duration was significant (both $F \mathrm{~s}<1$ ). $P_{\mathrm{r}}$ was above chance (greater than 0 ) in all four conditions (all $p s<.001)$.

\section{Discussion}

Experiment 2 used a cover task designed to prevent intentional encoding of face information. It was plausible

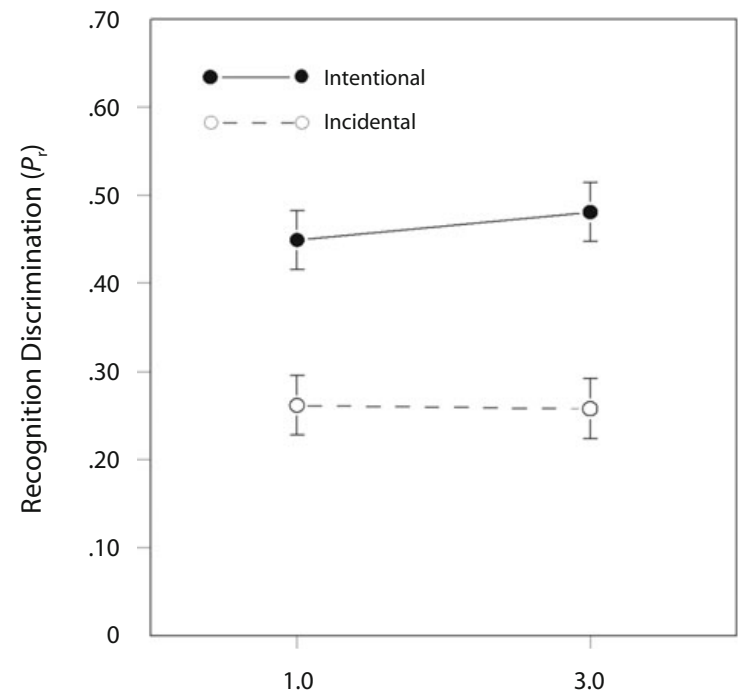

Stimulus Duration (sec)

Figure 2. $P_{\mathrm{r}}$ in Experiment 2, as a function of memory condition and stimulus duration. Error bars show SEs (per Loftus \& Masson, 1994). and easy (as reflected in the accuracy of counting). Participants in the intentional condition recognized faces better than did those in the incidental condition. There was no main effect or interaction involving stimulus duration: In both conditions, recognition memory was no better at the longer $(3.0-\mathrm{sec})$ than at the shorter $(1.0-\mathrm{sec})$ stimulus duration. This suggests that relatively automatic encoding of previously unfamiliar faces occurs within $1.0 \mathrm{sec}$ and that intentional encoding of previously unfamiliar faces enhances subsequent recognition discrimination, regardless of whether the face was presented for only $1.0 \mathrm{sec}$ or for $3.0 \mathrm{sec}$. The finding that recognition discrimination was above chance in the incidental condition suggests that some component face-encoding processes are relatively automatic. However, the intent to remember a human face presented for only $1.0 \mathrm{sec}$ produced a large effect on memory. This suggests that some controlled face-encoding processes can enhance memory, even if a face is presented for only $1.0 \mathrm{sec}$. An additional $2.0 \mathrm{sec}$ of stimulus duration produced no additional enhancement of memory, although a large effect of memory condition remained.

Thus, the findings of Experiment 2 reveal that intentional-memory participants showed enhanced recognition discrimination on human faces that were presented for either 1.0 or $3.0 \mathrm{sec}$. However, faces are somewhat unique in that all people have expertise in recognizing faces (Gauthier \& Nelson, 2001), and face encoding may depend on special, dedicated processing modules (Farah, Wilson, Drain, \& Tanaka, 1998; but see Gauthier \& Logothetis, 2000).

\section{EXPERIMENT 3}

In Experiment 3, I focused on whether or not the findings of Experiment 2 would be replicated if participants in the intentional condition were instructed to attend to another kind of stimulus instead of faces. Birds were selected because they are nonface stimuli that are about as complex and detailed as faces.

\section{Method}

Participants. A total of 80 undergraduates (40 female) consented to participate in a study investigating how people process visual information.

Design and Procedure. A $2 \times 2$ mixed model design was used, with memory condition (incidental vs. intentional) manipulated between participants and stimulus duration ( $1.0 \mathrm{vs} .3 .0 \mathrm{sec})$ manipulated within participants. At the start of the experiment, participants were given the same cover task as that used in Experiment 2: All participants read written instructions that stated that they would see pictures of cars, chairs, birds, and human faces, and that their task was to count the number of cars they saw. Memory condition was manipulated by the presentation of written instructions that informed the participants in the intentional condition that they would subsequently be asked to recognize the birds they saw. The participants in the incidental condition did not receive this information.

The methods were similar to those of Experiment 2: The participants viewed 74 stimuli-18 cars, 18 chairs, 20 birds, and 18 faces - with half of the stimuli of each type presented for each of two stimulus durations $(1.0$ or $3.0 \mathrm{sec})$. After reporting the total number of cars they saw, participants made old-new recognition judgments on a total of 40 bird pictures (20 old and 20 new) presented in a random order. Each test bird was shown for $8.0 \mathrm{sec}$. 


\section{Results}

Cover-task performance. The overall number of cars reported $(M=17.90, S E=0.11)$ did not differ from the actual number of cars presented $[t(79)=0.82, p=.42]$. Participants in the intentional $(M=18.03, S E=0.15)$ and incidental $(M=17.80, S E=0.16)$ conditions showed comparable performance $[t(78)=1.05, p=.30]$.

Hit rate, false alarm rate, and recognition bias. The hit rate was higher in the intentional $(M=.63, S E=$ $.02)$ than in the incidental $(M=.44, S E=.02)$ condition $[F(1,78)=55.2, p<.001, d=0.64]$. The false alarm rate did not differ between the intentional $(M=.33, S E=.02)$ and incidental $(M=.30, S E=.02)$ conditions $[t(78)=$ $0.87, p=.39] . B_{\mathrm{r}}$ was more conservative in the incidental $(M=.36, S E=.02)$ than in the intentional $(M=.48, S E=$ $.02)$ condition $[F(1,78)=18.4, p<.001, d=0.94]$.

Recognition discrimination. The main evidence concerns $P_{\mathrm{r}}$ in the two memory conditions at each of the two stimulus durations (see Figure 3). $P_{\mathrm{r}}$ was higher in the intentional than in the incidental condition $[F(1,78)=33.5$, $p<.001, d=0.98] . P_{\mathrm{r}}$ was higher for the $3.0-\mathrm{sec}$ than for the 1.0-sec stimulus duration $[F(1,78)=16.4, p<$ $.001, d=0.54]$. The interaction between memory condition and stimulus duration was not significant $(F<1) . P_{\mathrm{r}}$ was above chance (greater than 0 ) in all four conditions (all $p \mathrm{~s}<.001$ ).

\section{Discussion}

Experiment 3 was designed to replicate and extend the findings of Experiment 2, in which participants in the intentional condition were instructed to remember human faces. As in Experiment 2, there was a large effect of memory condition: Participants in the intentional condition recognized birds better than did those in the incidental

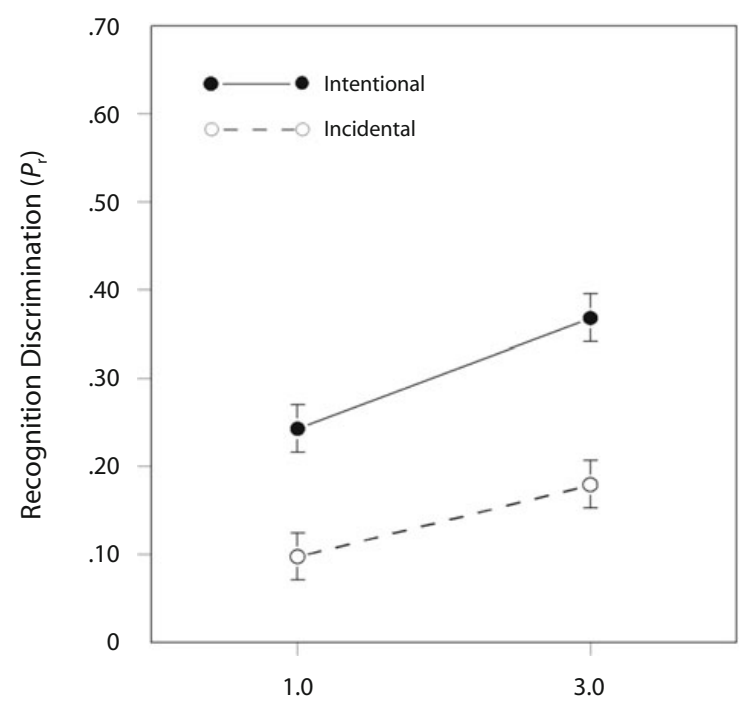

Stimulus Duration (sec)

Figure 3. $P_{\mathrm{r}}$ in Experiment 3, as a function of memory condition and stimulus duration. Error bars show $S E$ s. condition. In contrast to the findings of Experiment 2, in both the incidental and the intentional condition, recognition discrimination was higher at the longer $(3.0-\mathrm{sec})$ stimulus duration than at the shorter $(1.0-\mathrm{sec})$ stimulus duration. Although effective face encoding (in Experiment 2) did not improve beyond a stimulus duration of $1.0 \mathrm{sec}$, effective bird encoding (in Experiment 3 ) did. The finding that recognition discrimination was above chance in the incidental condition when birds were presented for only $1.0 \mathrm{sec}$ suggests that some component processes involved in nonface stimulus encoding are relatively automatic. However, the intent to remember a bird presented for only $1.0 \mathrm{sec}$ enhanced subsequent recognition discrimination, which suggests that some controlled stimulus-encoding processes enhance memory, even if a nonface pictorial stimulus is presented for only $1.0 \mathrm{sec}$.

\section{EXPERIMENT 4}

The findings of Experiments 2 and 3 revealed that intentional-memory instructions enhance subsequent recognition memory for human faces, as well as for stimuli (such as bird pictures), even if a pictorial stimulus is presented for only $1.0 \mathrm{sec}$. Experiment 4 was designed to investigate a possible lower limit of this enhancement, as well as to replicate and extend the previous findings by including another type of stimulus: ape faces. Two short stimulus durations were used $(0.5$ and $2.0 \mathrm{sec})$. With the same cover task as that used in Experiments 2 and 3, some participants were also informed that their memory for human faces, ape faces, or birds would be tested. Other participants did not receive this information, but their memory too was tested on either human faces, ape faces, or birds.

\section{Method}

Participants. A total of 192 undergraduates (96 female) participated as in Experiments 2 and 3.

Design and Procedure. A $2 \times 3 \times 2$ mixed model design manipulated memory condition (incidental vs. intentional) and stimulus type (human face vs. ape face vs. bird; see Figure 1) between participants, and stimulus duration $(0.5$ vs. $2.0 \mathrm{sec})$ within participants. At the start of the experiment, all of the participants were told to perform the "counting cars" cover task as in Experiments 2 and 3 . The memory condition was manipulated by the presentation of written instructions that informed the participants in the three intentional-memory cells that they would subsequently be asked to recognize one of the three kinds of stimuli (i.e., human faces, ape faces, or birds) that they saw. The participants in the three incidental memory cells did not receive this information.

The procedure was similar to that used in Experiments 2 and 3: The participants viewed 74 stimuli-18 cars, 18 of each of the nontarget stimuli, and 20 of the target stimuli - with half of the stimuli of each type presented for each of two stimulus durations $(0.5 \mathrm{or} 2.0 \mathrm{sec})$. As before, the ISI was $0 \mathrm{sec}$. After the pictures were presented, the participants reported the total number of cars they saw and then made old-new recognition judgments on human faces, ape faces, or birds. A total of 40 test stimuli-20 old and 20 new-were presented in a random order. Each test stimulus was shown for $8.0 \mathrm{sec}$.

\section{Results}

Several $2 \times 3 \times 2$ (memory condition $\times$ stimulus type $\times$ stimulus duration) mixed model ANOVAs were conducted, as were planned comparisons ( $t$ tests). For 
Table 1

Recognition Data in Experiments 4 and 5

\begin{tabular}{|c|c|c|c|c|c|c|c|c|c|c|c|c|}
\hline \multirow{3}{*}{$\begin{array}{l}\text { Stimulus } \\
\text { Type }\end{array}$} & \multicolumn{4}{|c|}{ Hit Rate } & \multicolumn{4}{|c|}{ False Alarm Rate } & \multicolumn{4}{|c|}{$\operatorname{Bias}\left(B_{\mathrm{r}}\right)$} \\
\hline & \multicolumn{2}{|c|}{ Intentional } & \multicolumn{2}{|c|}{$\underline{\text { Incidental }}$} & \multicolumn{2}{|c|}{ Intentional } & \multicolumn{2}{|c|}{ Incidental } & \multicolumn{2}{|c|}{ Intentional } & \multicolumn{2}{|c|}{ Incidental } \\
\hline & $M$ & $\overline{S E}$ & $M$ & $\overline{S E}$ & $M$ & $\overline{S E}$ & $M$ & $\overline{S E}$ & $M$ & $\overline{S E}$ & $M$ & $\overline{S E}$ \\
\hline \multicolumn{13}{|c|}{ Experiment 4} \\
\hline Ape faces & .63 & .02 & .54 & .02 & .35 & .02 & .33 & .02 & .48 & .02 & .43 & .02 \\
\hline Human faces & .52 & .02 & .46 & .02 & .22 & .02 & .21 & .02 & .31 & .02 & .28 & .02 \\
\hline Birds & .57 & .02 & .47 & .02 & .38 & .03 & .34 & .02 & .44 & .02 & .39 & .02 \\
\hline Overall & .57 & .01 & .49 & .01 & .32 & .01 & .30 & .01 & .41 & .01 & .37 & .01 \\
\hline \multicolumn{13}{|c|}{ Experiment 5} \\
\hline Ape faces & .65 & .02 & .56 & .02 & .32 & .02 & .33 & .02 & .48 & .02 & .43 & .02 \\
\hline Human faces & .59 & .02 & .47 & .02 & .22 & .02 & .21 & .02 & .35 & .02 & .28 & .02 \\
\hline Birds & .60 & .02 & .44 & .02 & .36 & .02 & .32 & .02 & .46 & .02 & .36 & .02 \\
\hline Overall & .61 & .02 & .49 & .02 & .30 & .01 & .29 & .02 & .43 & .02 & .36 & .02 \\
\hline
\end{tabular}

each stimulus type, a $2 \times 2$ (memory condition $\times$ stimulus duration) mixed model ANOVA was also conducted. Only significant findings will be reported, unless nonsignificant findings are of particular theoretical interest.

Cover-task performance. The overall number of cars reported $(M=17.98, S E=0.07)$ did not differ from the actual number of cars presented $[t(191)=0.21, p=.83]$. Participants in the intentional $(M=17.96, S E=0.09)$ and incidental $(M=18.01, S E=0.09)$ conditions showed comparable performance $(F<1)$.

Hit rate, false alarm rate, and recognition bias. Although there was a main effect of stimulus duration on the hit rate $[F(1,186)=53.5, p<.001]$, it did not interact with stimulus type, memory condition, or both (all $p \mathrm{~s}>$.18). Table 1 shows the hit rate, the false alarm rate, and the recognition bias in the four between-participants conditions. The hit rate was higher on ape faces than on human faces and birds $[F(2,186)=10.0, p<.001]$. The false alarm rate was lower on human faces than on ape faces and birds $[F(2,186)=20.2, p<.001]$. Although $B_{\mathrm{r}}$ was conservative under all conditions, it was more conservative in the incidental than in the intentional condition $[F(1,186)=5.35, p=.02, d=0.33]$ and on human faces than on ape faces and birds $[F(2,186)=21.0, p<.001]$.

Recognition discrimination. The main data of interest concern $P_{\mathrm{r}}$.

All stimuli. Figure 4A shows $P_{\mathrm{r}}$ averaged across the three stimulus types in the two memory conditions and at each of the two stimulus durations. Overall, $P_{\mathrm{r}}$ was higher in the intentional condition than in the incidental condition $[F(1,186)=12.0, p=.001, d=0.50] . P_{\mathrm{r}}$ was higher at the $2.0-\mathrm{sec}$ than at the $0.5-\mathrm{sec}$ stimulus duration $[F(1,186)=56.3, p<.001, d=0.55]$. The main effect of stimulus type $[F(1,78)=9.89, p<.001]$ revealed that $P_{\mathrm{r}}$ was higher on human faces and ape faces than on birds. The two- and three-way interactions of memory condition, stimulus type, and stimulus duration were not significant (all $p \mathrm{~s}>.16$ ).

Planned comparisons revealed the major finding that $P_{\mathrm{r}}$ was higher in the intentional than in the incidental condition at both the $0.5-\sec [t(190)=2.26, p=.03, d=0.33]$ and the $2.0-\sec [t(190)=3.42, p=.001, d=0.49]$ stimulus duration. $P_{\mathrm{r}}$ was higher at the $2.0-\sec [t(96)=6.02$, $p<.001, d=0.64]$ than at the $0.5-\sec [t(96)=4.52, p<$
$.001, d=0.47]$ stimulus duration in both the intentional and the incidental condition. $P_{\mathrm{r}}$ was above chance (greater than 0) in all four conditions (all $p \mathrm{~s}<.005$ ).

Stimulus type. Figure 4 also shows $P_{\mathrm{r}}$ separately for each stimulus type. On human faces, $P_{\mathrm{r}}$ was higher in the intentional than in the incidental condition $[F(1,62)=4.18$, $p<.05, d=0.51]$ and at the $2.0-\mathrm{sec}$ than at the $0.5-\mathrm{sec}$ stimulus duration $[F(1,62)=34.1, p<.001, d=0.81]$. On ape faces, $P_{\mathrm{r}}$ was higher in the intentional than in the incidental condition $[F(1,62)=7.87, p=.007, d=0.70]$ and at the $2.0-\mathrm{sec}$ than at the 0.5 - sec stimulus duration $[F(1,62)=16.1, p<.001, d=0.61]$. On birds, $P_{\mathrm{r}}$ was marginally higher in the intentional than in the incidental condition $[F(1,62)=2.70, p=.10, d=0.41]$ and was significantly higher at the 2.0 -sec than at the 0.5 -sec stimulus duration $[F(1,62)=9.94, p=.002, d=0.35]$.

\section{Discussion}

The findings of Experiment 4 clarify and extend the findings of Experiments 1, 2, and 3. Although a shorter stimulus duration was used than in the three previous experiments, the effect of intent to remember was as large, and it was significant even at the 0.5 -sec stimulus duration. Another interesting finding is that recognition of human faces was better at the $2.0-\mathrm{sec}$ than at the $0.5-\mathrm{sec}$ stimulus duration, although in Experiment 2, it was not significantly better at the $3.0-\mathrm{sec}$ than at the 1.0 -sec stimulus duration. This comparison suggests that encoding of a human face beyond a stimulus duration of about $1.0 \mathrm{sec}$ or so, under either incidental or intentional conditions, does not enhance long-term recognition.

\section{EXPERIMENT 5}

The major finding of Experiment 4 was that recognition memory for pictorial stimuli is enhanced by intentional instructions, as well as by increased stimulus duration. However, it is possible that the cover task either caused dual-task interference (especially in the intentional condition) or resulted in diminished attention to stimuli other than cars (especially in the incidental condition). Although these effects might be in opposite directions, either possibility could have influenced the effect of intentional- versus incidental-memory instructions. In 
A

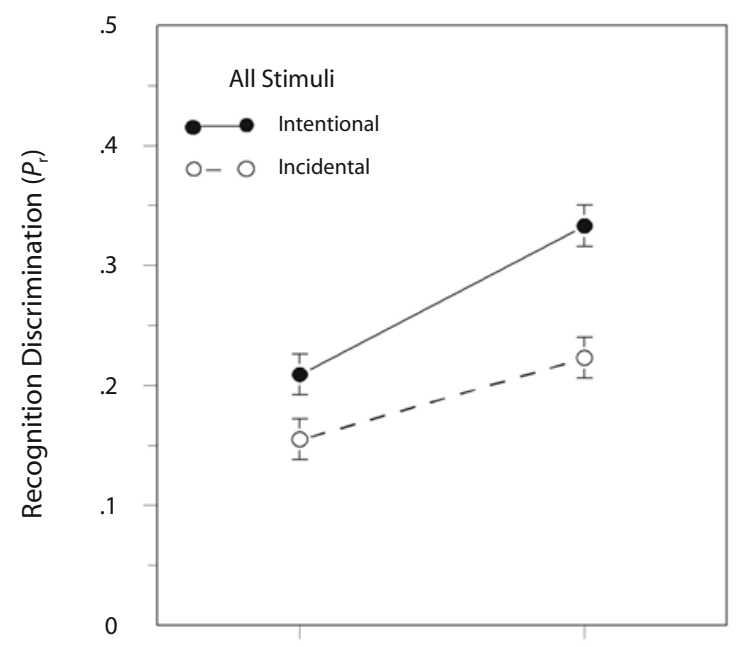

0.5

\section{C}

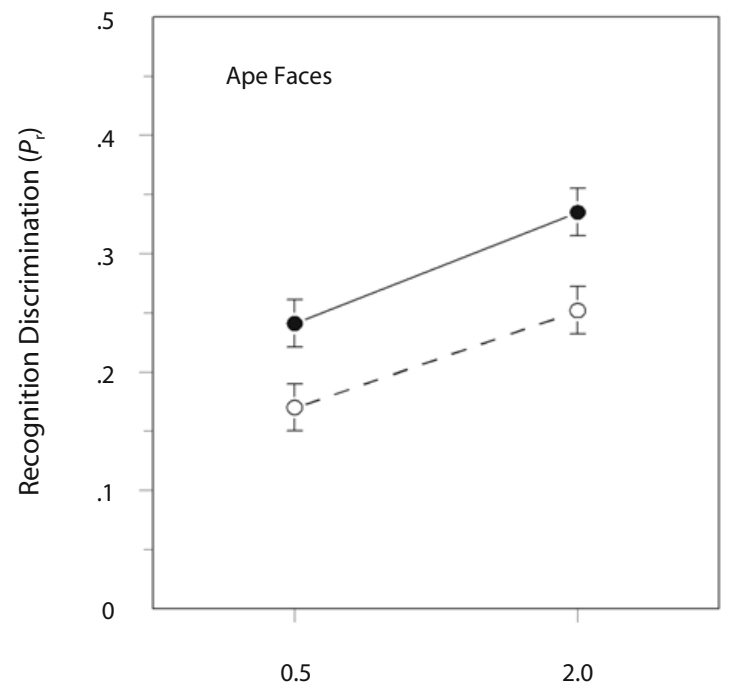

Stimulus Duration (sec)
B

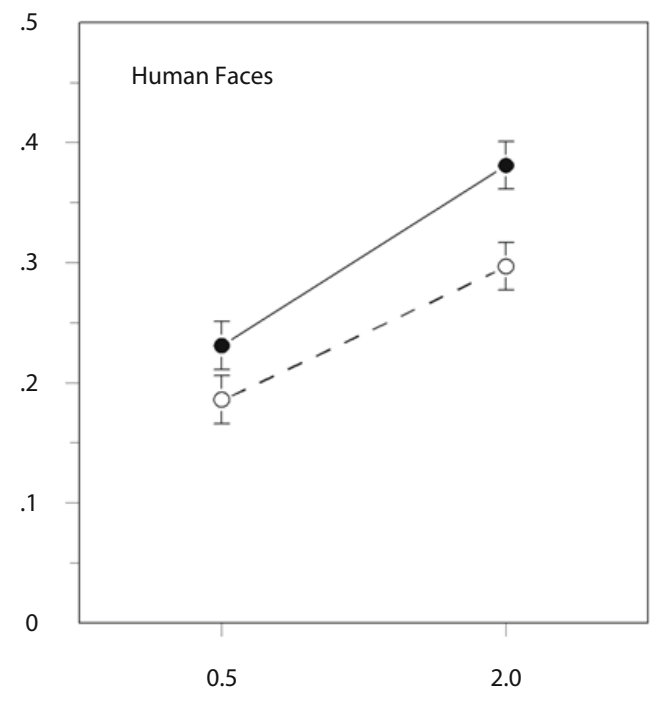

D

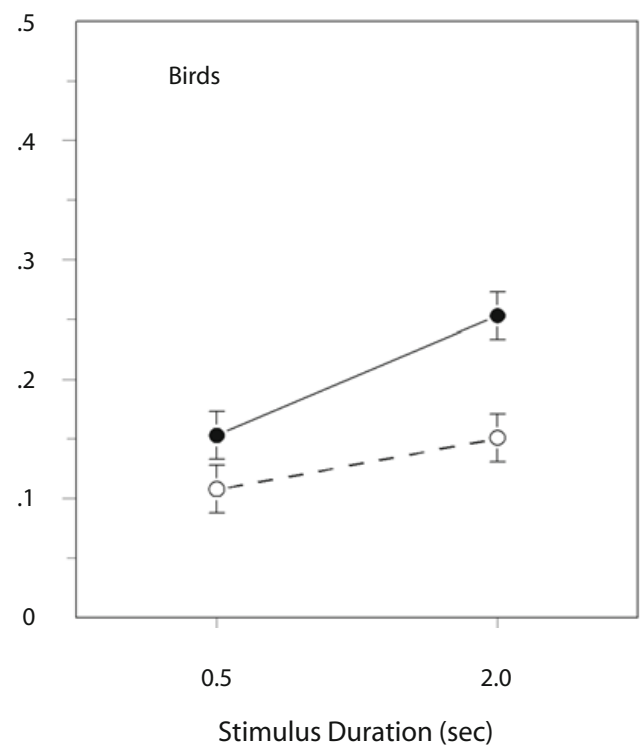

Figure 4. $P_{\mathrm{r}}$ in Experiment 4, as a function of memory condition and stimulus duration. $P_{\mathrm{r}}$ is shown for all stimulus types (panel A), as well as separately for participants tested on human faces (panel B), ape faces (panel C), and birds (panel D). Error bars show $S E$ s.

order to provide additional evidence regarding the intent to remember pictorial information, Experiment 5 used a cover story that was basically the same one that was used in Experiment 1.

\section{Method}

Participants. A total of 144 participants ( 72 female) consented to participate in an experiment on pictures and mood.

Materials and Design. The materials and design were identical to those used in Experiment 4. However, all of the participants were initially told that "we are interested in how your mood is affected by viewing a rapid series of pictures." The memory condition was then manipulated by the presentation of additional instructions only to intentional-memory participants, as in Experiment 4.

\section{Results}

Hit rate, false alarm rate, and recognition bias. $\mathrm{Al}-$ though there was a main effect of stimulus duration on hit rate $[F(1,138)=112.0, p<.001]$, it did not interact with stimulus type, memory condition, or both (all $p \mathrm{~s}>.05$ ). 
A

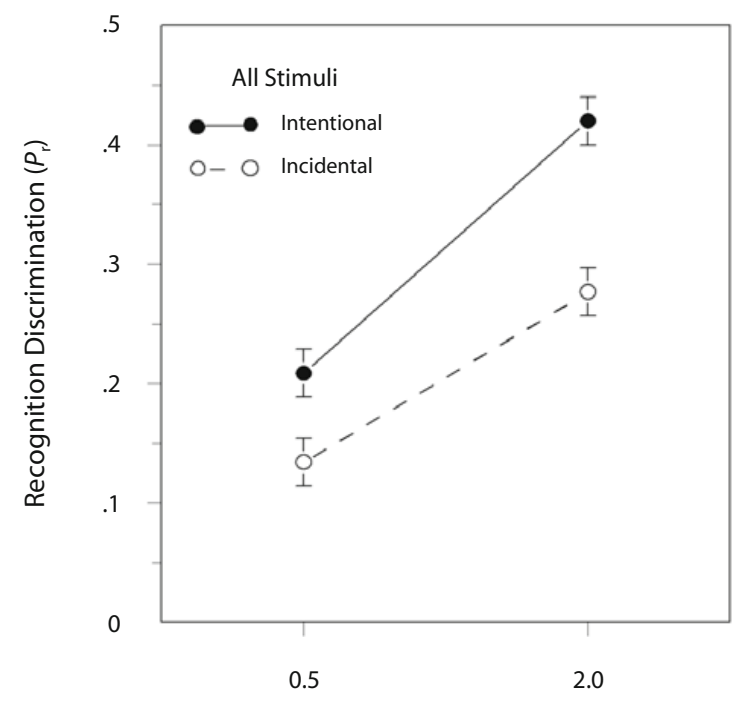

C

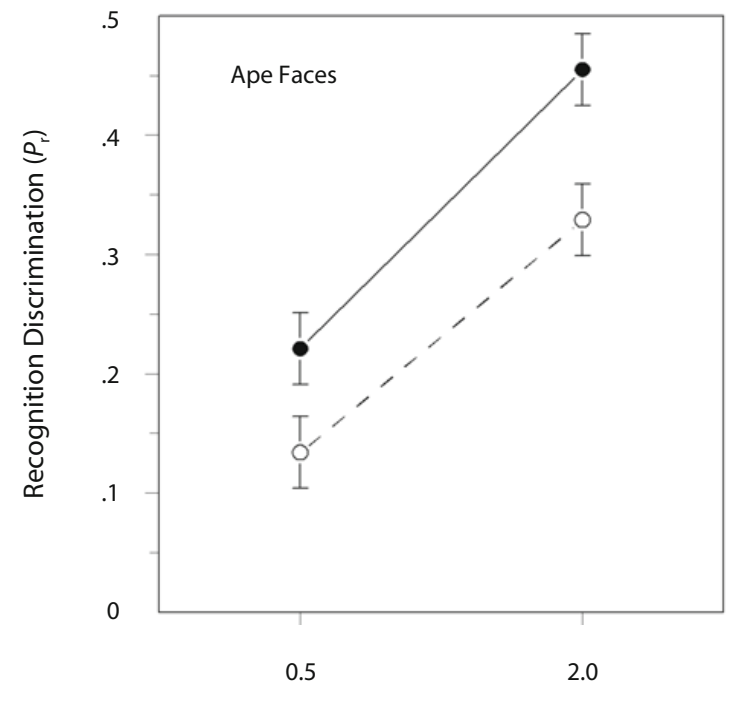

Stimulus Duration (sec)
B

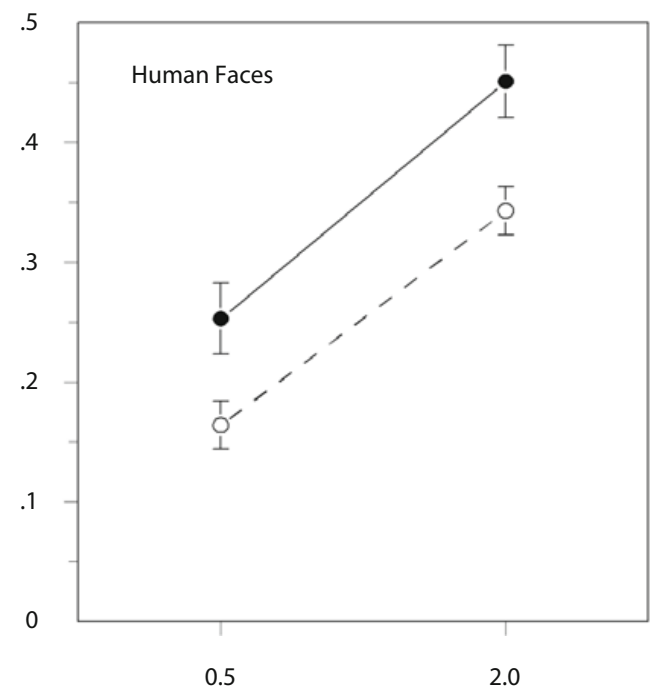

D

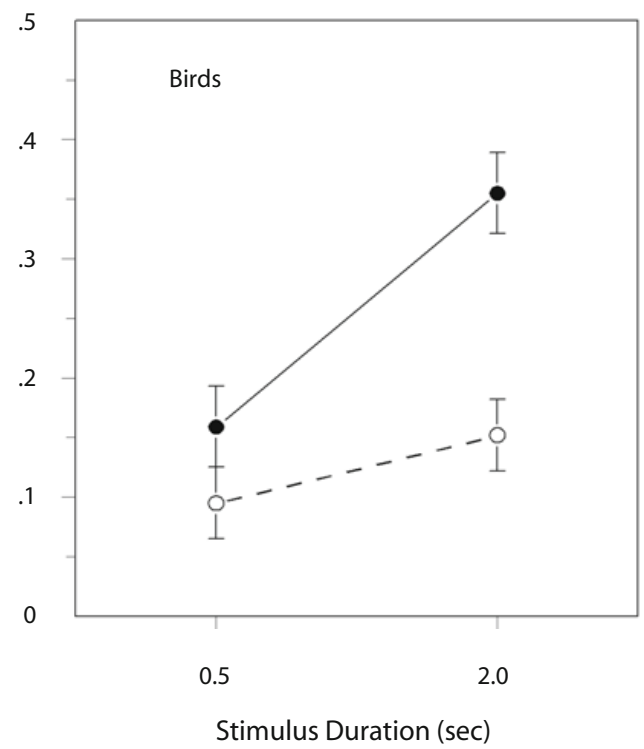

Figure 5. $P_{\mathrm{r}}$ in Experiment 5, as a function of memory condition and stimulus duration. $P_{\mathrm{r}}$ is shown for all stimulus types (panel A), as well as separately for participants tested on human faces (panel B), ape faces (panel C), and birds (panel D). Error bars show $S E$ s.

Table 1 shows the hit rate, the false alarm rate, and the recognition bias in the four between-participants conditions. The hit rate was higher on ape faces than on human faces and birds $[F(2,138)=6.84, p=.001]$. The false alarm rate was lower on human faces than on ape faces and birds $[F(2,138)=14.7, p=.001]$. Although $B_{\mathrm{r}}$ was conservative under all conditions, it was more conservative in the incidental than in the intentional condition $[F(1,138)=$ $11.2, p=.001, d=0.55]$ and on human faces than on ape faces and birds $[F(2,138)=14.1, p<.001]$.
Recognition discrimination. The main data of interest concern $P_{\mathrm{r}}$.

All stimuli. Figure 5A shows $P_{\mathrm{r}}$ averaged across the three stimulus types in the two memory conditions and at each of the two stimulus durations. As in Experiment 4, overall, $P_{\mathrm{r}}$ was higher in the intentional than in the incidental condition $[F(1,138)=22.3, p<.001, d=0.75] . P_{\mathrm{r}}$ was higher at the $2.0-\mathrm{sec}$ than at the 0.5 -sec stimulus duration $[F(1,138)=127.9, p<.001, d=0.97]$. The main effect of stimulus type $[F(2,138)=9.57, p<.001]$ revealed 
that $P_{\mathrm{r}}$ was higher on human faces and ape faces than on birds. However, as in Experiment 4, the two- and threeway interactions of memory condition, stimulus type, and stimulus duration were not significant (all $p \mathrm{~s}>.18$ ).

Planned comparisons revealed the major finding that $P_{\mathrm{r}}$ was higher in the intentional than in the incidental condition at both the $0.5-\sec [t(142)=2.67, p=.01, d=0.44]$ and the $2.0-\sec [t(142)=4.77, p<.001, d=0.79]$ stimulus duration. $P_{\mathrm{r}}$ was higher at the $2.0-\sec [t(71)=9.33$, $p<.001, d=1.21]$ than at the $0.5-\sec [t(71)=6.44, p<$ $.001, d=0.82]$ stimulus duration in both the intentional and the incidental condition. $P_{\mathrm{r}}$ was above chance (greater than 0 ) in all four conditions (all $p \mathrm{~s}<.001$ ).

Stimulus type. Figure 5 also shows $P_{\mathrm{r}}$ separately for each stimulus type. On human faces, $P_{\mathrm{r}}$ was higher in the intentional than in the incidental condition $[F(1,46)=5.20$, $p=.03, d=0.98]$ and at the $2.0-\mathrm{sec}$ than at the $0.5-\mathrm{sec}$ stimulus duration $[F(1,46)=52.9, p<.001, d=1.02]$. On ape faces, $P_{\mathrm{r}}$ was higher in the intentional than in the incidental condition $[F(1,46)=10.5, p=.002, d=0.92]$ and at the $2.0-\mathrm{sec}$ than at the $0.5-\mathrm{sec}$ stimulus duration $[F(1,46)=40.8, p<.001, d=1.38]$. On birds, $P_{\mathrm{r}}$ was higher in the intentional than in the incidental condition $[F(1,46)=10.5, p=.002, d=0.99]$ and at the 2.0 -sec than at the 0.5 -sec stimulus duration $[F(1,46)=20.2, p<$ $.001, d=0.72]$.

Comparisons with data from Experiment 4. A $2 \times$ $2 \times 3$ mixed model ANOVA was conducted to investigate possible effects of a cover story (Experiment 4) versus a cover task (Experiment 5) on $P_{\mathrm{r}}$. As can be seen by comparing Figures 4 and 5, the significant effect of memory condition was not moderated by the cover-task versus cover-story manipulation $[F(1,332)=1.28, p=$ .26]. However, the effect of stimulus duration was larger in Experiment 5 than in Experiment $4[F(1,332)=15.9$, $p<.001]$. Although the between-experiments difference was not significant at the 0.5 -sec stimulus duration $[t(334)=0.54, p=.59], P_{\mathrm{r}}$ was higher in Experiment 5 at the $2.0-\mathrm{sec}$ stimulus duration $[t(334)=3.38, p=.001$, $d=0.37]$.

\section{Discussion}

The findings of Experiment 5 replicate and clarify the findings of Experiment 4. As in Experiment 4, the effect of intentional memory on recognition discrimination was significant at both the 0.5 -sec and 2.0-sec stimulus durations. However, stimulus duration had a larger effect in Experiment 5 than in Experiment 4: Recognition discrimination was slightly better at the longer stimulus duration in Experiment 5, which used a cover story, than it was in Experiment 4, which used a cover task.

\section{GENERAL DISCUSSION}

Nearly a century of research on effects of intent to remember on memory performance reveals a literature containing many methodological issues and empirical contradictions. Previous experiments that used rehearsable verbal materials (such as words), relatively long stimulus durations, and recall tests of memory showed somewhat reliable effects of intent to remember. However, experiments that used pictorial materials (such as human faces) combined with recognition tests of memory found little or no effect of intent to remember.

I investigated the limits of effects of the intent to remember information on memory under stringent conditions that involved memory for briefly presented, presumably unrehearsable pictorial stimuli, such as human faces. As the methodology became more stringent (especially in terms of shorter stimulus durations in Experiments 4 and 5), the effect of instructions to remember stimuli remained reliable. New findings regarding effects of intent to remember, as well as the role of controlled information processing, are revealed. The major new finding is that people can enhance their subsequent recognition memory by means of an intent to remember, even if a stimulus is presented for as little as $0.5-1.0 \mathrm{sec}$. Across experiments, the effect size for the comparison of intentional- versus incidental-memory conditions ranged from medium $(d=$ $0.50)$ to large $(d=0.98)$.

The findings of Experiment 1 reveal that intentionalmemory instructions enhance recognition memory for human faces. In Experiment 2, this finding was replicated with birds. In Experiment 3, this finding was shown to extend downward to stimulus durations of $1.0-3.0 \mathrm{sec}$. In Experiments 4 and 5, this finding was replicated and extended to include ape faces, as well as human faces and birds, presented for only $0.5-2.0 \mathrm{sec}$.

These findings show that the intent to remember pictorial information enhances recognition memory, even if a person views a human face, an ape face, or a bird for as little as $0.5-1.0 \mathrm{sec}$. Previous skeptical conclusions about effects of intent to remember on memory-conclusions that were based mainly on verbal materials presented for longer durations - should be viewed with caution. The present findings reveal that people given intentional-memory instructions show enhanced memory for pictorial stimuli, even under stringent methodological conditions.

How does intent to remember affect encoding of information, resulting in better subsequent recognition memory performance? Consider several kinds of explanations.

\section{Rehearsal}

Memory for pictorial stimuli, such as those used in the present study, is enhanced by increasing stimulus duration (Tversky \& Sherman, 1975), and the present evidence supports that finding. Inserting a blank ISI of several seconds (e.g., 3-9 sec) between pictorial stimuli, during which people may rehearse a stimulus, also enhances subsequent recognition memory (see, e.g., Read, 1979). However, there is no evidence that people can rehearse a pictorial stimulus when another pictorial stimulus follows immediately, and in the present experiments, the ISI was $0 \mathrm{sec}$. If rehearsal is a viable explanation, the present findings are the first to show that people can rehearse a pictorial stimulus when other to-be-processed pictorial stimuli follow it immediately. Although rehearsal can easily explain the effects of intent to remember in experiments using verbal materials (such as words), rehearsal seems to be an ad hoc, strained, and untenable explanation of the present findings. 


\section{Depth of Processing}

Although it is possible that participants in the intentional condition encoded human or ape faces by judging the honesty or likableness of them within $0.5 \mathrm{sec}$, it is difficult to assume that they could do something similar when they encoded birds. No levels-of-processing manipulation was used, so this explanation must assume that participants know that deep processing levels enhance memory and that they know how to process stimuli at a deep level. Both assumptions seem untenable. Under intentional conditions, people do not necessarily use the optimal way for processing information (Craik, Özçelik, $\&$ Luo, 2008). The levels-of-processing framework cannot easily provide an account of the present findings.

\section{Attentional Allocation}

Another possible explanation is that, under intentional conditions, people can rapidly (within $0.5-1.0 \mathrm{sec}$ ) mobilize attentional resources. In this explanation, attentionalresource mobilization does not involve rehearsing a stimulus or processing it at a deeper level. It may involve rapidly encoding a distinctive feature of the stimulus or, perhaps, a more configural, or holistic, encoding process (see, e.g., Rakover, 2002).

Using a very different methodology, Reeves and Sperling (1986) theorized that a so-called attentional gate can open within about 300-400 msec, allowing for effective shortterm memory encoding of rapidly presented visual information. They did not suggest any precise process by which this information is encoded or stored in memory. In addition to providing evidence on effects of intent to remember, the present findings support Reeves and Sperling's hypothesis, although over a much longer retention interval - one on the order of several minutes, not several seconds.

A comparison of the results of Experiments 4 and 5 also lends support to the attentional hypothesis. At the longer $(2.0-\mathrm{sec})$ stimulus duration, recognition memory was slightly worse in Experiment 4, which used a cover task, than it was in Experiment 5, which used a cover story. Although this difference could be attributed to dual-task interference (in Experiment 4), it seems unlikely that a working-memory task (updating a mathematical count of cars) would compete for the same attentional resources as a pictorial-encoding task (encoding human faces, ape faces, or birds). Another, perhaps more likely, explanation is that this slight difference is attributable to a controlled lack of attention to stimuli other than cars in Experiment 4 when they were presented at the longer stimulus duration.

\section{Conclusion}

The intent to remember pictorial information facilitates long-term recognition memory. This facilitation occurs under stringent conditions, such as using pictorial stimuli briefly presented at an ISI of $0 \mathrm{sec}$, a recognition test instead of a recall test, and a relatively long retention interval. The facilitation effect may be explained in terms of earlier suggestions that attentional resources can be mobilized within several hundred milliseconds. Although additional experiments are needed to reject alternative ex- planations, the present findings are the first to suggest that, if a person is instructed to try to remember a pictorial stimulus, a rapid mobilization of attentional resources may lead to an enhanced encoding of it.

\section{AUTHOR NOTE}

I thank Shlomo Bentin for supplying the pictures used in Experiments 2-5. I thank many student researchers who helped collect these data, including Melissa Banks, Frank Bosco, Matthew Cloninger, Jeremy Fleming, Catherine Gault, Erik Johnson, Aaron Richmond, and Tyson Roth. I also thank Tim Curran, Alice Healy, Douglas Hintzman, Moshe Naveh-Benjamin, Dan Zakay, and an anonymous reviewer for comments and suggestions on an earlier version of the manuscript. Portions of these data were presented at the 49th Annual Meeting of the Psychonomic Society, Chicago, November 2008. Correspondence concerning this article should be addressed to R. A. Block, Department of Psychology, Montana State University, Bozeman, MT 59717-3440 (e-mail: block@) montana.edu).

\section{REFERENCES}

Bower, G. H., \& KARLIN, M. B. (1974). Depth of processing pictures of faces and recognition memory. Journal of Experimental Psychology, 103, 751-757

Bruce, V. (1988). Recognising faces. Hove, U.K.: Erlbaum.

Carmel, D., \& Bentin, S. (2002). Domain specificity versus expertise: Factors influencing distinct processing of faces. Cognition, 83, 1-29.

Coin, C., \& Tiberghien, G. (1997). Encoding activity and face recognition. Memory, 5, 545-568.

Craik, F. I. M., \& Lockhart, R. S. (1972). Levels of processing: A framework for memory research. Journal of Verbal Learning \& Verbal Behavior, 11, 671-684.

Craik, F. I. M., Özçelik, E., \& Luo, L. (2008, November). Is “shortterm consolidation" simply "deep processing?" Paper presented at the 49th Annual Meeting of the Psychonomic Society, Chicago. Abstracts of the Psychonomic Society, 13, 9.

EAGLE, M., \& LeITER, E. (1964). Recall and recognition in intentional and incidental learning. Journal of Experimental Psychology, 68, 58-63.

Ellis, H. D., \& Young, A. W. (1989). Are faces special? In A. W. Young \& H. D. Ellis (Eds.), Handbook of research on face processing (pp. 1-26). Amsterdam: North-Holland.

Estes, W. K., \& DA Polito, F. (1967). Independent variation of information storage and retrieval processes in paired-associate learning. Journal of Experimental Psychology, 75, 18-26.

Farah, M. J., Wilson, K. D., Drain, M., \& Tanaka, J. N. (1998). What is "special" about face perception? Psychological Review, 105, 482-498.

Gauthier, I., \& Logothetis, N. K. (2000). Is face recognition not so unique after all? Cognitive Neuropsychology, 17, 125-142.

Gauthier, I., \& Nelson, C. A. (2001). The development of face expertise. Current Opinion in Neurobiology, 11, 219-224.

HASHER, L., \& ZACKS, R. T. (1979). Automatic and effortful processes in memory. Journal of Experimental Psychology: General, 108, 356-388.

Hasher, L., \& ZaCKs, R. T. (1984). Automatic processing of fundamental information: The case of frequency of occurrence. American Psychologist, 39, 1372-1388.

Hintzman, D. L., \& Rogers, M. K. (1973). Spacing effects in picture memory. Memory \& Cognition, 1, 430-434.

Hyde, T. S., \& JENKINS, J. J. (1973). Recall for words as a function of semantic, graphic, and syntactic orienting tasks. Journal of Verbal Learning \& Verbal Behavior, 12, 471-480.

INTERQUEST (1998). FACES: The ultimate composite picture (Version 3.0) [Computer software]. Saint-Hubert, Quebec, Canada: Author.

Lewin, C., \& Herlitz, A. (2002). Sex differences in face recognitionWomen's faces make the difference. Brain \& Cognition, 50, 121-128. LofTus, G. R., \& Masson, M. E. J. (1994). Using confidence intervals in within-subject designs. Psychonomic Bulletin \& Review, 1, 476-490.

Marmie, W. R., \& Healy, A. F. (2004). Memory for common objects: Brief intentional study is sufficient to overcome poor recall of US coin features. Applied Cognitive Psychology, 18, 445-453.

Meumann, E. (1913). The psychology of learning: An experimental in- 
vestigation of the economy and technique of memory (J. W. Baird, Trans.) (3rd ed.). New York: Appleton.

Neill, W. T., Beck, J. L., Bottalico, K. S., \& Molloy, R. D. (1990). Effects of intentional versus incidental learning on explicit and implicit tests of memory. Journal of Experimental Psychology: Learning, Memory, \& Cognition, 16, 457-463.

NeImark, E., \& Saltzman, I. J. (1953). Intentional and incidental learning with different rates of stimulus-presentation. American Journal of Psychology, 66, 618-621.

Palermo, R., \& Rhodes, G. (2007). Are you always on my mind? A review of how face perception and attention interact. Neuropsychologia, 45, 75-92.

Posner, M. I., \& SNyder, C. R. R. (1975). Attention and cognitive control. In R. L. Solso (Ed.), Information processing and cognition: The Loyola symposium (pp. 55-85). Hillsdale, NJ: Erlbaum.

Postman, L. (1964). Short-term memory and incidental learning. In A. W. Melton (Ed.), Categories of human learning (pp. 145-201). New York: Academic Press.

Postman, L., \& Phillips, L. W. (1954). Studies in incidental learning: I. The effects of crowding and isolation. Journal of Experimental Psychology, 48, 48-56.

RAKOVER, S. S. (2002). Featural vs. configurational information in faces: A conceptual and empirical analysis. British Journal of Psychology, 93, 1-30.

RAKOVER, S. S., \& CAHLON, B. (2001). Face recognition: Cognitive and computational processes. Amsterdam: Benjamins.

READ, J. D. (1979). Rehearsal and recognition of human faces. American Journal of Psychology, 92, 71-85.

ReEves, A., \& Sperling, G. (1986). Attention gating in short-term visual memory. Psychological Review, 93, 180-206.

Saltzman, I. J. (1953). The orienting task in incidental and intentional learning. American Journal of Psychology, 66, 593-597.

Saltzman, I. J., \& AtKinson, R. L. (1954). Comparisons of incidental and intentional learning after different numbers of stimulus presentations. American Journal of Psychology, 67, 521-524.

SAltZMAn, I. J., \& CARTEReTTE, T. S. (1959). Incidental and intentional learning of isolated and crowded items. American Journal of Psychology, 72, 230-235.

SCHNEIDER, W., \& SHIFFrin, R. M. (1977). Controlled and automatic human information processing: I. Detection, search, and attention. Psychological Review, 84, 1-66.

ShafFer, W., \& ShifFrin, R. M. (1972). Rehearsal and storage of visual information. Journal of Experimental Psychology, 92, 292-296.

Shellow, S. M. (1923). Individual differences in incidental memory. Archives of Psychology, 10(Whole No. 64).

Shiffrin, R. M., \& SchneIder, W. (1977). Controlled and automatic human information processing: II. Perceptual learning, automatic attending, and a general theory. Psychological Review, 84, 127-190.

Snodgrass, J. G., \& Corwin, J. (1988). Pragmatics of measuring rec- ognition memory: Applications to dementia and amnesia. Journal of Experimental Psychology: General, 117, 34-50.

TVERSKy, B., \& Sherman, T. (1975). Picture memory improves with longer on time and off time. Journal of Experimental Psychology: Human Learning \& Memory, 1, 114-118.

Watkins, M. J., \& Graefe, T. M. (1981). Delayed rehearsal of pictures. Journal of Verbal Learning \& Verbal Behavior, 20, 276-288.

WEAVER, G. E. (1974). Effects of poststimulus study time on recognition of pictures. Journal of Experimental Psychology, 103, 799-801.

Willingham, D. T. (2007). Cognition: The thinking animal (3rd ed.). Upper Saddle River, NJ: Prentice Hall.

YounG, A. W. (ED.) (1998). Face and mind. New York: Oxford University Press.

ZeChmeister, E. B., \& NYBERG, S. E. (1982). Human memory: An introduction to research and theory. Monterey, CA: Brooks/Cole.

\section{NOTES}

1. All $p$ values and effect-size estimates $(d \mathrm{~s})$ concerning previous findings of interest (Eagle \& Leiter, 1964; Hyde \& Jenkins, 1973) that are reported here were calculated from reported means and standard deviations; they were not reported by the original researchers.

2. In all five experiments, the numbers of male and female participants were equal in order to ensure the cross-sex generalizability of the findings. In addition, ancillary analyses of the human-face data from Experiments 1, 3, 4, and 5 were conducted with participant sex as a variable in order to investigate the so-called same-sex effect on recognition memory. In agreement with some but not all of the extant research, the predominant finding was an uncrossed interaction in which female participants were slightly better at recognizing female faces, as compared with the other three combinations of participant sex and face sex (e.g., Lewin \& Herlitz, 2002). Results of these analyses are available on request.

3. FACES automatically includes a logo at the lower right-hand side of each image, partially covering the person's neck. I thought that this logo would be distracting, and, in order to make the faces appear more natural, I retouched each face, deleting the logo and the neck area.

4. Two alternative measures of discrimination and bias were also analyzed in all experiments: the $A^{\prime}$ (recognition discrimination) and $B_{\mathrm{D}}^{\prime \prime}$ (recognition bias) measures and the logistic signal-detection measures, $d_{\mathrm{L}}$ and $C_{\mathrm{L}}$ (see Snodgrass \& Corwin, 1988). However, no analysis revealed any pattern of findings different from those for the $P_{\mathrm{r}}$ and $B_{\mathrm{r}}$ measures; that is, each main effect and interaction was consistently either significant or nonsignificant, regardless of which model of recognition discrimination and bias was used.

(Manuscript received May 8, 2008; revision accepted for publication February 5, 2009.) 